\title{
Inquérito populacional sobre a funcionalidade das pessoas com lesão medular no Brasil: estudo de protocolo
}

\section{Population survey on the functionality of people with spinal cord injury in Brazil: a protocol study}

\author{
Daniela Mitiyo Odagiri Utiyama ${ }^{1}$, (Dábio Marcon Alfieri², (DLinamara Rizzo Battistella ${ }^{3}$
}

\begin{abstract}
RESUMO
A pesquisa InSCl (International spinal cord injury) foi desenvolvida para descrever a saúde e o bem-estar de indivíduos com lesão medular (LM) em relação à comunidade local. Por isto, objetivo deste estudo será descrever as características pessoais, fatores ambientais, de saúde, de qualidade de vida, de trabalho dos indivíduos que vivem com lesão medular no Brasil e comparar os dados com outros países participantes da pesquisa. Este estudo deverá ser de caráter transversal observacional. Os indivíduos com LM serão recrutados no Instituto de Medicina Física e de Reabilitação (IMREA) do Hospital das Clínicas da Faculdade de Medicina da Universidade de São Paulo, na Rede de Reabilitação Lucy Montoro (IRLM) e na Associação Fluminense de Reabilitação (AFR). Participarão do estudo 400 indivíduos de ambos os sexos com idade igual ou superior a 18 anos com diagnóstico de lesão medular de origem traumática cujo tempo de lesão esteja superior a 3 meses. Os voluntários realizarão uma avaliação inicial por meio de questionário com 125 perguntas sobre problemas de saúde, atividade e participação, independência nas atividades de vida diária, trabalho, fatores ambientais e pessoais, serviços de saúde e qualidade de vida. As associações entre as variáveis serão feitas testes de correlação de Pearson ou Spearman. Modelos simples de regressão linear ou logística também poderão ser usados de acordo com os dados obtidos. Os procedimentos de processamento e ajuste de dados obedecerão às recomendações das Diretrizes Cross-Cultural Survey (CCSG) e ao fortalecimento do Relatório de Estudos Observatórios em Epidemiologia (STROBE).
\end{abstract}

Palavras-chave: Traumatismos da Medula Espinal, Qualidade de Vida, Inquéritos Epidemiológicos

${ }^{1}$ Instituto de Medicina Física e Reabilitação do Hospital das Clínicas - IMREA HCFMUSP

${ }^{2}$ Centro de Pesquisa Clínica, Instituto de Medicina Física e Reabilitação do Hospital das Clínicas IMREA HCFMUSP

${ }^{3}$ Faculdade de Medicina, Universidade de São Paulo

\section{Correspondência}

Fábio Marcon Alfieri

E-mail: fabioalfieri@usp.br

Recebido: 05 maio 2020

Aceito: 27 Abril 2020

\section{Como citar}

Utiyama DMO, Alfieri FM, Battistella LR. Inquérito populacional sobre a funcionalidade das pessoas com lesão medular no Brasil: estudo de protocolo. Acta Fisiatr. 2020;27(1):11-19.

DOI: 10.11606/issn.2317-0190.v27i1a172051

\begin{abstract}
An InSCl (International Spinal Cord Injury) survey was developed to describe health and to be well subject to spinal cord injuries $(\mathrm{SCl})$ in relation to the local community. Therefore, the objective of this study will be well subject to spinal cord injuries $(\mathrm{SCl})$ in relation to the local community. Therefore, the objective of this study will be to describe how personal resources, environmental, health, quality of life, work conditions of individuals who suffer from spinal cord injury in Brazil and data comparison with other countries participating in the research. This study must be of an observational cross-sectional character. Individuals with $\mathrm{SCl}$ will be recruited at the Institute of Physical Medicine and Rehabilitation (IMREA) of the Hospital de Clínicas of the Faculty of Medicine of the University of São Paulo, the Lucy Montoro Rehabilitation Network (IRLM) and the Fluminense Rehabilitation Association (AFR). Participate in the study 400 individuals with both sexes aged 18 years or older diagnosed with traumatic spinal cord injury whose injury time is longer than 3 months. The volunteers will carry out an initial evaluation through a questionnaire with 125 questions about health problems, activity and participation, independence in activities of daily living, work, environmental and personal factors, health services and quality of life. Variations between variables can be made using Pearson or Spearman correlation. Simple linear or logistic regression models can also be used according to the data obtained. The procedures for processing and adjusting data obey the recommendations of the Intercultural Research of Guidelines (CCSG) and the strengthening of the Report on Observatory Studies in Epidemiology (STROBE).
\end{abstract}

Keywords: Spinal Cord Injuries, Quality of Life, Health Surveyss 


\section{INTRODUÇÃO}

A lesão medular (LM) pode ser traumática decorrente de acidente ou não traumática devido a doenças. Independentemente da etiologia, provoca alterações na função motora ou na sensibilidade. No mundo, afeta entre 250.000 a 500.000 pessoas por ano, resultando em acometimentos na saúde, limitando as atividades diárias e a interferindo na qualidade de vida. ${ }^{1}$

Nos últimos anos, o Levantamento Comunitário Internacional da Comunidade de Lesão Medular (InSCI), o Estudo de Coorte Suíça de Lesão Medular (SwiSCI) e as categorias da CIF (Classificação Internacional de Funcionalidade, Incapacidade e Saúde) têm sido vistos como as abordagens mais adequadas para identificar as necessidades dos indivíduos com lesão medular.

A Conferência Mundial da Saúde aprovou em maio de 2014 o Plano de Ação Global de Incapacidade da Organização Mundial da Saúde (OMS) 2014-2021: Melhor saúde para todas as pessoas com deficiência. ${ }^{1}$ Os principais objetivos do Plano Global de Ação de Incapacidade são: reduzir barreiras e melhorar o acesso aos serviços de saúde, tecnologia assistiva e reabilitação baseada na comunidade, bem como fortalecer a coleta de dados relevantes em uma base internacionalmente comparável.

O Plano de Ação Global de Incapacidade foi estruturado com base na implementação do Relatório Mundial sobre Deficiência (2011) e do Relatório Internacional de Perspectivas sobre Lesão Medular (IPSCI, 2013). ${ }^{2,3}$ O relatório IPSCI resume a importância da lesão medular (LM), tanto a nível individual como social. As principais recomendações do relatório IPSCI referem-se à melhoria da resposta do setor de saúde à $L M$, à autonomia de pessoas com LM e suas famílias, à redução de atitudes negativas em relação às pessoas com LM, a melhoria da acessibilidade dos edifícios, bem como o transporte e a informação, a melhoria da integração do mercado de trabalho e a promoção de pesquisas adequadas e a coleta de dados sobre pessoas que vivem com LM. O relatório IPSCI enfatiza a necessidade de obter melhores dados à partir de modelos de boas práticas em países em diferentes estágios de desempenho econômico e desenvolvimento social.

A pesquisa InSCl (International spinal cord injury) foi desenvolvida para descrever a experiência vivida por pessoas com LM nos países participantes, em particular para coletar dados abrangentes sobre 0 funcionamento, a saúde e o bem-estar destes indivíduos em relação à comunidade local. $\mathrm{A}$ Classificação Internacional de Funcionalidade, Incapacidade e Saúde (CIF), ${ }^{4}$ que descreve o funcionamento e a deficiência como uma interação complexa entre a condição de saúde de um indivíduo e fatores contextuais, ${ }^{4,5}$ é um modelo de referência reconhecido e uma classificação para a coleta de dados. Consequentemente, a InSCl foi desenvolvida no contexto das categorias CIF relevantes para LM. ${ }^{6,7,8}$ Embora os dados obtidos com a pesquisa não possam orientar diretamente práticas, pesquisas e políticas no campo da deficiência e reabilitação, a pesquisa $\mathrm{InSCl}$ no contexto do LHS-SCI fornecerá provas sobre a experiência vivida e as necessidades das pessoas que vivem com LM, o que auxiliará como um insumo importante para futuras práticas, políticas e estratégias de pesquisa.

$\mathrm{O}$ desenho e as experiências da primeira pesquisa comunitária do estudo de coorte da lesão da medula espinal na Suíça (SwiSCI 2012) orientaram o desenvolvimento do protocolo de estudo InSCl..$^{9,10}$ O SwiSCI (2012) representa um estudo epidemiológico pioneiro para a medição da experiência vivida da LM usando a CIF como o principal modelo de dados. 0 estudo também forneceu informações sobre aspectos operacionais críticos para o projeto de uma pesquisa comunitária para LM. ${ }^{11,12}$

A primeira pesquisa da comunidade $\mathrm{InSCl}$ deveria ser implementada em mais de 30 países em 2017, sendo o Brasil o único país da América Latina a participar do estudo. Devido às diferenças entre os países, a implementação operacional variará de acordo com as condições de cada local.

\section{OBJETIVO}

O objetivo deste estudo será fornecer uma base de dados para descrever e identificar as características pessoais, os fatores ambientais, de saúde, de qualidade de vida, de trabalho dos indivíduos que vivem com lesão medular no Brasil e comparar os dados com outros países participantes da pesquisa.

\section{MÉTODO}

Este estudo deverá ser de caráter transversal observacional. Os indivíduos com lesão medular serão recrutados no Instituto de Medicina Física e de Reabilitação do Hospital das Clínicas da Faculdade de Medicina da Universidade de São Paulo (IMREA), na Rede de Reabilitação Lucy Montoro (IRLM) e na Associação Fluminense de Reabilitação (AFR) através de convite verbal, desde que atendam aos critérios de inclusão e exclusão descritos a seguir.

Este estudo foi submetido e aprovado pela Comissão de Ética e Pesquisa do Hospital das Clínicas da Faculdade de Medicina da Universidade de São Paulo.

Os indivíduos que realizarem a avaliação através do telefone não necessitarão de consentimento por escrito. Os que tiverem condições de chegar ao local da avaliação de forma independente, darão por escrito seu consentimento autorizando sua participação na pesquisa.

Participarão do estudo 400 indivíduos de ambos os sexos com idade igual ou superior a 18 anos. Como critérios de inclusão: indivíduos de ambos sexos com idade superior ou igual à 18 anos; diagnóstico de lesão medular cujo tempo de lesão esteja superior a 3 meses.

Não serão incluídos nesse estudo indivíduos com lesão medular de etiologias congênitas; distúrbios de espinha bífida, doenças neurodegenerativas (esclerose múltipla e esclerose lateral amiotrófica) e lesões de nervo periférico; indivíduos internados realizando atendimento de reabilitação pela primeira vez e indivíduos no atendimento agudo.

Primeiramente foi realizada a tradução do questionário para o português com as adaptações necessárias. Os voluntários realizarão uma avaliação inicial por meio de questionário com 125 perguntas sobre dados gerais, problemas de saúde, atividade e participação, independência nas atividades de vida diária, trabalho, fatores ambientais e pessoais, serviços de saúde e qualidade de vida.

\section{Análise dos dados}

A primeira etapa da análise será obter estatísticas descritivas para as distribuições de cada uma das variáveis de interesse, que serão usadas para verificar observações periféricas e erros de dados. Serão examinadas as associações parciais apropriadas entre as variáveis de interesse. A fim de verificar as associações entre as variáveis, serão feitos testes de correlação de Pearson ou Spearman de acordo com a normalidade ou não dos dados. Modelos simples de regressão linear ou logística também poderão ser usados de acordo com os dados obtidos. A fim de garantir a mais alta qualidade dos dados processados, os procedimentos de processamento e ajuste de dados obedecerão às recomendações das Diretrizes Cross-Cultural Survey (CCSG $)^{13}$ 
internacionalmente aceitas e ao fortalecimento do Relatório de Estudos Observatórios em Epidemiologia (STROBE). ${ }^{14}$

Os dados serão apresentados em tabelas visando mostrar ao leitor os dados descritivos em relação aos dados psicossociais, funcionalidade, problemas de saúde, trabalho e fatores ambientais. Por fim, serão feitas correlações também apresentadas em tabelas que mostrem as relações entre as variáveis como tempo de estudo, escolaridade, tempo de lesão, renda e questões como qualidade de vida, aspectos psicossociais, trabalho e funcionalidade.

\section{DISCUSSÃO}

Este estudo terá como objetivo descrever e identificar as características pessoais, os fatores ambientais, de saúde, de qualidade de vida, de trabalho dos indivíduos que vivem com lesão medular no Brasil e comparar os dados com outros países participantes da pesquisa. Os participantes da pesquisa como referido anteriormente pertencem a 28 países desenvolvidos e países em desenvolvimento. Contudo, uma caracterização completa em indivíduos que vivem em países em desenvolvimento pode trazer informações concretas de como os indivíduos com LM conseguem enfrentar as dificuldades no âmbito social, psicológico e físico, que é o caso dos indivíduos no Brasil.

Conhecer esta realidade permitirá não apenas a comparação entre os países, mas sim traçar diretrizes de atenção a estes indivíduos que muitas vezes são excluídos pela sociedade.

Acredita-se que com os resultados obtidos por esse instrumento, não somente os profissionais da saúde, mais aqueles que de certa forma interagem com indivíduos com lesão medular, poderão modificar o olhar sobre essa população focando mais na funcionalidade destes indivíduos.

Saber quais são as dificuldades de saúde, estruturais e ambientais que interferem para que esses indivíduos desenvolvam a funcionalidade pode ajudar no processo de reabilitação não somente dos aspectos físicos, mas também psicossociais. Além disto, este instrumento poderá fornecer subsídios de como o processo de reabilitação pôde contribuir na visão dos próprios indivíduos para a melhora da funcionalidade, uma vez que trará aspectos avaliativos de questões como mobilidade, independência das atividades de vida diária, dentre outras.

\section{REFERÊNCIAS}

1. World Health Organization. Draft WHO global disability action plan 2014-2021: Better health for all people with disability. Geneva: WHO; 2014

2. Bickenbach JE, Officer A, Shakespears T, von Groote P. International perspectives on spinal cord injury. Geneva: WHO; 2013.

3. Institute of Medicine. Best care at lower cost: the path to continuously learning health care in America. Washington, DC: National Academies; 2013. Doi: https://doi. org/10.17226/13444

4. ICF - International Classification of Functioning, Disability and Health. Geneva: WHO; 2001.

5. Geyh S, Peter C, Müller R, Bickenbach JE, Kostanjsek $\mathrm{N}$, Ustün BT, et al. Personal Factors of the International Classification of Functioning, Disability and Health in the literature - a systematic review and content analysis. Disabil Rehabil. 2011;33(1314):1089-102. Doi: http://dx.doi.org/10.3109/09638 288.2010.523104

6. Cieza A, Kirchberger I, Biering-Sørensen F, Baumberger M, Charlifue S, Post MW, et al. ICF Core Sets for individuals with spinal cord injury in the long-term context. Spinal Cord. 2010;48(4):305-12. Doi: http://dx.doi.org/10.1038/sc.2009.183
7. Kirchberger I, Cieza A, Biering-Sørensen F, Baumberger M, Charlifue S, Post MW, et al. ICF Core Sets for individuals with spinal cord injury in the early post-acute context. Spinal Cord. 2010;48(4):297-304. Doi: http://dx.doi.org/10.1038/sc.2009.128

8. Fekete C, Boldt C, Post M, Eriks-Hoogland I, Cieza A, Stucki G. How to measure what matters: development and application of guiding principles to select measurement instruments in an epidemiologic study on functioning. Am J Phys Med Rehabil. 2011;90(11 Suppl 2):S29-38. Doi: http://dx.doi.org/10.1097/ PHM.0b013e318230fe41

9. Brinkhof MW, Fekete C, Chamberlain JD, Post MW Gemperli A; SwiSCl Study Group. Swiss national community survey on functioning after spinal cord injury: Protocol, characteristics of participants and determinants of non-response. J Rehabil Med. 2016;48(2):120-30. Doi: http://dx.doi. org/10.2340/16501977-2050

10. Post MW, Brinkhof MW, von Elm E, Boldt C, Brach M, Fekete C, et al. Design of the Swiss Spinal Cord Injury Cohort Study. Am J Phys Med Rehabil. 2011;90(11 Suppl 2):S5-16. Doi: http://dx.doi.org/10.1097/ PHM.0b013e318230fd41

11. Fekete C, Segerer W, Gemperli A, Brinkhof MW; SwiSCl Study Group. Participation rates, response bias and response behaviours in the community survey of the Swiss Spinal Cord Injury Cohort Study (SwiSCI). BMC Med Res Methodol. 2015;15:80. Doi: http://dx.doi. org/10.1186/s12874-015-0076-0

12. Prodinger B, Ballert CS, Brach M, Brinkhof MW, Cieza A, Hug K, et al. Toward standardized reporting for a cohort study on functioning: The Swiss Spinal Cord Injury Cohort Study. J Rehabil Med. 2016;48(2):18996. Doi: http://dx.doi.org/10.2340/16501977-2026

13. Survey Research Center. Guidelines for Best Practice in Cross - Cultural Surveys. Ann Arbor, MI: Survey Research Center, Institute for Social Research, University of Michigan; 2010.

14. von Elm E, Altman DG, Egger M, Pocock SJ, Gøtzsche $\mathrm{PC}$, Vandenbroucke JP, et al. The Strengthening the Reporting of Observational Studies in Epidemiology (STROBE) statement: guidelines for reporting observational studies. Bull World Health Organ. 2007;85(11):867-72. Doi: http://dx.doi.org/10.2471/ blt.07.045120 


\section{Inquérito Internacional sobre Lesão Medular}

\section{INFORMAÇÕES PESSOAIS}

1- Indique o seu gênero

$\square$ Masculino

$\square$ Feminino

2- Por favor, informe a sua data de nascimento.

Dia/mês/ano

3- Em que país você nasceu?

4- Qual é o seu estado civil atual?

$\square$ Solteiro(a)

$\square$ Casado(a)

$\square$ União estável

$\square$ Divorciado(a) ou separado(a)

$\square$ Viúvo(a)

5- Com quem você mora? (selecione todas as opções que se apliquem)

$\square$ Moro Sozinho

$\square$ Com crianças com menos de 14 anos; quantas são?

$\square$ Com jovens entre os 14 e os 18 anos; quantos são?

$\square$ Com pessoas entre os 18 e os 64 anos; quantas são?

$\square$ Com pessoas com mais de 64 anos; quantas são?

$\square$ Moro numa instituição (por exemplo, lar de idosos)

6- Você recebe assistência/ajuda nas atividades do dia-a-dia, em casa ou fora de casa?

$\square$ Não

$\square$ Sim, sou ajudado pelas seguintes pessoas

Selecione todas as opções que se apliquem:

$\square$ Familia

$\square$ Amigos

$\square$ Profissionais/cuidadores

7- Qual é o grau de escolaridade mais elevado que você já concluiu?

$\square$ Não sabe ler/escrever

Ensino Fundamental

$\square$ Ensino Médio

$\square$ Educação para Jovens e Adultos / Ensino Supletivo

$\square$ Ensino Superior

$\square$ Pós-Graduação

$\square$ Outro. Especifique:

8- No total, quantos anos de escolaridade ou de estágios profissionalizantes você já completou?

$\square$ Antes da lesão medular:___ anos

$\square$ Depois da lesão medular: anos

9- Considerando os rendimentos de todas as pessoas que vivem com você e recebem uma remuneração/salário, qual é a renda mensal da família? (salário mínimo em 2018: R\$ 954,00)

Sem rendimento

$\square$ Até 1 salário mínimo

$\square$ Entre 1 a 2 salários mínimos

$\square$ Entre 2 e 3 salários mínimos

$\square$ Entre 3 e 5 salários mínimos

$\square$ Entre 5 a 10 salários mínimos

$\square$ Entre 10 e 20 salários mínimos

$\square$ Mais de 20 salários mínimos

10- Pense na escada que você vê abaixo como uma representação da posição das pessoas no Brasil.

No alto da escada estão as pessoas que vivem melhor - as que tem mais dinheiro, mais educação e empregos mais respeitados. Próximas ao pé da escada estão as pessoas que vivem pior - que tem menos dinheiro, meno educação e que tem piores empregos ou nem sequer tem emprego. Quanto mais alto você estiver na escada, mais próximo(a) está das pessoas que estão no alto; quanto mais baixo você estiver, mais próximo(a) está das pessoas que estão no pé da escada.

Em que lugar você se colocaria na escada?

Coloque um "X" no degrau onde acha que você se encontra nesta fase da sua vida, em relação às outras pessoas que vivem no Brasil.

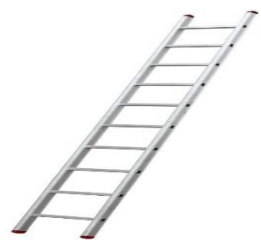

\section{CARACTERÍSTICAS DA LESÃO}

11- Por favor descreva o nível da sua lesão medular:

$\square$ Paraplegia (movimento e sensibilidade normal nos membros superiores)

$\square$ Tetraplegia (falta ou alteração nos movimentos ou na sensibilidade dos membros superiores e inferiores, isto é, nos braços e nas pernas)

12- A sua lesão é completa ou incompleta?

$\square$ Completa (incapaz de sentir e mexer qualquer parte do corpo abaixo do nível da sua lesão)

$\square$ Incompleta (capaz de mexer ou sentir alguma(s) parte(s) do corpo abaixo do nivel da sua lesão)

13- Por favor, indique a causa da sua lesão medular (selecione todas as opções que se apliquem):

Causada por traumatismo (por favor, assinale todas as opções que se apliquem; por exemplo, se assinalar "acidente durante o trabalho", especifique também se foi devido a uma queda ou se teve outra causa)

$\square$ Acidente durante prática desportiva

$\square$ Acidente durante atividade de lazer/entretenimento

$\square$ Acidente durante o trabalho

$\square$ Acidente de aviação

$\square$ Lesão devida a violência (tiro, facada, etc.)

$\square$ Queda de menos de 1 metro de altura

$\square$ Queda de mais de 1 metro de altura

$\square$ Outra causa (especifique)

Causada por doença (por favor, assinale todas as opções que se apliquem)

$\square$ Artroses da coluna vertebral

$\square$ Tumor - benigno

$\square$ Tumor - maligno (câncer)

$\square$ Problema vascular/circulatório (isquemia, hemorragia, malformações)

$\square$ Infeção (bactéria, vírus)

$\square$ Outra doença (especifique)

14- Por favor, indique, de forma tão precisa quanto possível, a data em que ocorreu a sua lesão medular:

Dia/mês/ano

\section{ENERGIA E SENTIMENTOS}

As perguntas a seguir pretendem avaliar a forma como se sentiu e como você tem passado as últimas 4 semanas. Para cada pergunta, assinale a resposta que melhor descreve a forma como se sentiu.

Por quanto tempo, nas últimas 4 semanas, você...

\begin{tabular}{|l|c|c|c|c|c|}
\hline & Sempre & $\begin{array}{c}\text { A maior } \\
\text { parte do } \\
\text { tempo }\end{array}$ & $\begin{array}{c}\text { Algum } \\
\text { tempo }\end{array}$ & $\begin{array}{c}\text { Pouco } \\
\text { tempo }\end{array}$ & Nenhum \\
\hline $\begin{array}{l}\text { 15- Se sentiu cheio(a) de } \\
\text { vitalidade? }\end{array}$ & $\square$ & $\square$ & $\square$ & $\square$ & $\square$ \\
\hline $\begin{array}{l}\text { 16-S e sentiu muito } \\
\text { nervoso(a)? }\end{array}$ & $\square$ & $\square$ & $\square$ & $\square$ & $\square$ \\
\hline $\begin{array}{l}\text { 17- Se sentiu tão } \\
\text { deprimido(a) que nada } \\
\text { o(a) animava? }\end{array}$ & $\square$ & $\square$ & $\square$ & $\square$ & $\square$ \\
\hline $\begin{array}{l}\text { 18- Se sentiu calmo(a) e } \\
\text { tranquilo(a)? }\end{array}$ & $\square$ & $\square$ & $\square$ & $\square$ & $\square$ \\
\hline $\begin{array}{l}\text { 19- Se sentiu com muita } \\
\text { energia? }\end{array}$ & $\square$ & $\square$ & $\square$ & $\square$ & $\square$ \\
\hline $\begin{array}{l}\text { 20- Se sentiu } \\
\text { deprimido(a)? }\end{array}$ & $\square$ & $\square$ & $\square$ & $\square$ & $\square$ \\
\hline $\begin{array}{l}\text { 21- Se sentiu } \\
\text { estafado(a)? }\end{array}$ & $\square$ & $\square$ & $\square$ & $\square$ & $\square$ \\
\hline 22- Se sentiu feliz? & $\square$ & $\square$ & $\square$ & $\square$ & $\square$ \\
\hline $\begin{array}{l}\text { 23- Se sentiu } \\
\text { cansado(a)? }\end{array}$ & $\square$ & $\square$ & $\square$ & $\square$ \\
\hline
\end{tabular}

PROBLEMAS DE SAÚDE

Para os problemas de saúde seguintes, assinale a gravidade de cada problema para você nos últimos 3 meses. Se você teve um determinado problema de 
saúde, assinale se recebeu ou não tratamento para esse problema (como por exemplo, tomar um medicamento ou receber tratamentos médicos ou de outros profissionais de saúde)

1- Sem problema e 5- Muito problemático

\begin{tabular}{|c|c|c|c|c|c|}
\hline & 1 & 2 & 3 & 45 & $\begin{array}{c}\text { Recebeu/recebe } \\
\text { tratamento? }\end{array}$ \\
\hline $\begin{array}{l}\text { 24- Problemas com o sono } \\
\text { Por ex. dificuldade em adormecer ou } \\
\text { dificuldade em dormir durante toda a noite e } \\
\text { acordar cedo }\end{array}$ & $\square$ & $\square$ & $\square$ & $\exists \square$ & $\begin{array}{l}\square \operatorname{Sim} \\
\square \text { Não }\end{array}$ \\
\hline \begin{tabular}{|l|} 
25- Alterações intestinais \\
Por ex. diarreia, incontinência para fezes \\
("acidentes") e obstipação (prisão de ventre) \\
\end{tabular} & $\square$ & $\square$ & $\square$ & $\overline{7}$ & $\begin{array}{l}\square \operatorname{Sim} \\
\square \text { Não }\end{array}$ \\
\hline \begin{tabular}{|l|} 
26- Infeções urinárias \\
Por ex. infeções da bexiga ou dos rins
\end{tabular} & $\square$ & $\square$ & $\square$ & $\exists \square$ & $\begin{array}{l}\square \text { Sim } \\
\square \text { Não }\end{array}$ \\
\hline \begin{tabular}{|l|} 
27- Alterações vesicais \\
Por ex. incontinência ("acidentes"), cálculos \\
("pedras") na bexiga ou rins, problemas renais, \\
perdas de urina e refluxo de urina (para os rins)
\end{tabular} & $\square$ & $\square$ & $\square$ & $\nabla \square$ & $\begin{array}{l}\square \operatorname{Sim} \\
\square \text { Não }\end{array}$ \\
\hline $\begin{array}{l}\text { 28- Disfunção sexual } \\
\text { Por ex. dificuldade com a excitação sexual, } \\
\text { ereção, lubrificação e capacidade de atingir o } \\
\text { orgasmo }\end{array}$ & $\square$ & $\square$ & $\square$ & $\nabla \square$ & $\begin{array}{l}\square \operatorname{Sim} \\
\square \text { Não }\end{array}$ \\
\hline \begin{tabular}{|l} 
29- Contraturas/Rigidez articular \\
Por ex. limitação na amplitude de movimento \\
de uma articulação \\
\end{tabular} & $\square$ & $\square$ & $\square$ & $\vec{\square} \square$ & $\begin{array}{l}\square \operatorname{Sim} \\
\square \text { Não }\end{array}$ \\
\hline $\begin{array}{l}\text { 30- Espasmos musculares, espasticidade, } \\
\text { inclui movimentos musculares bruscos e } \\
\text { incontroláveis, como contrações ou } \\
\text { espasmos }\end{array}$ & $\square$ & $\square$ & $\square$ & $\exists \square$ & $\begin{array}{l}\square \operatorname{Sim} \\
\square \text { Não }\end{array}$ \\
\hline \begin{tabular}{|l|} 
31- Úlceras de pressão ("escaras") \\
Iniciam-se como uma zona vermelha na pele e \\
podem progredir para uma ferida infeccionada
\end{tabular} & $\square$ & $\square$ & $\square$ & $\nabla \square$ & $\begin{array}{l}\square \operatorname{Sim} \\
\square \text { Não }\end{array}$ \\
\hline $\begin{array}{l}\text { 32- Problemas respiratórios } \\
\text { Infecções respiratória e problemas que levam a } \\
\text { dificuldades para respirar e para eliminar } \\
\text { secreções ("expectoração") }\end{array}$ & $\square$ & $\square$ & $\square$ & $\square$ & $\begin{array}{l}\square \operatorname{Sim} \\
\square \text { Não }\end{array}$ \\
\hline \begin{tabular}{|l|} 
33- Lesões causadas pela perda de \\
sensibilidade \\
Por ex. queimaduras por líquidos quentes ou \\
por se sentar muito perto de uma fonte de calor \\
(aquecedor ou lareira)
\end{tabular} & $\square$ & $\square$ & 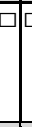 & $\square$ & $\begin{array}{l}\square \operatorname{Sim} \\
\square \text { Não }\end{array}$ \\
\hline $\begin{array}{l}\text { 34- Problemas circulatórios } \\
\text { Envolve o inchaço das veias dos pés, das } \\
\text { pernas ou das mãos ou a ocorrência de } \\
\text { coágulos sanguíneos (trombose) }\end{array}$ & $\square$ & $\square$ & $\bar{\square}$ & $\exists \square$ & $\begin{array}{l}\square \operatorname{Sim} \\
\square \text { Não }\end{array}$ \\
\hline $\begin{array}{l}\text { 35- Disreflexia autonômica } \\
\text { Subida rápida da pressão arterial e suores, } \\
\text { com manchas na pele, arrepios, dilatação das } \\
\text { pupilas e dor de cabeça }\end{array}$ & $\square$ & $\square$ & & $\nabla \square$ & $\begin{array}{l}\square \operatorname{Sim} \\
\square \text { Não }\end{array}$ \\
\hline $\begin{array}{l}\text { 36- Hipotensão ortostática } \\
\text { Forte sensação de tontura/desmaio após uma } \\
\text { mudança de posição do corpo. Causada por } \\
\text { uma rápida queda da pressão arterial }\end{array}$ & $\square$ & & & 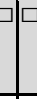 & $\begin{array}{l}\square \operatorname{Sim} \\
\square \text { Não }\end{array}$ \\
\hline $\begin{array}{l}\text { 37- Dor } \\
\text { Sentir dor no dia-a-dia }\end{array}$ & $\square$ & $\square$ & $\square$ & $\square$ & $\begin{array}{l}\square \operatorname{Sim} \\
\square \text { Não }\end{array}$ \\
\hline
\end{tabular}

38- Por favor, assinale a gravidade da sua dor, fazendo um círculo em volta do número que melhor descreve a sua pior dor na última semana: 0 - Sem dor 10- Pior dor que posso imaginar

$\begin{array}{lllllllllll}0 & 1 & 2 & 3 & 4 & 5 & 6 & 7 & 8 & 9 & 10\end{array}$

39- Por favor, faça uma lista de até 5 problemas de saúde que também o incomodam:

$\square$ Não tenho outros problemas de saúde

40 - Por favor, indique se fuma, já fumou ou nunca fumou:

$\square$ Nunca fumei

$\square$ Ex-tabagista

$\square$ Tabagista ativo (inclusive fumantes ocasionais)

\section{ATIVIDADES E PARTICIPAÇÃO}

A seção seguinte refere-se a problemas que enfrenta na sua vida. Por favor, leve em consideração os dias bons e os dias ruins nas últimas 4 semanas.

1 - sem dificuldade e 5 - muito difícil

\begin{tabular}{|c|c|c|c|c|c|}
\hline $\begin{array}{l}\text { Nas últimas } 4 \text { semanas, qual foi o nível de } \\
\text { dificuldade para... }\end{array}$ & 1 & 2 & 3 & 4 & 5 \\
\hline 41- ... cumprir sua rotina diária? & $\square$ & $\square$ & $\square$ & $\square$ & $\square$ \\
\hline 42- ... lidar com o stress? & $\square$ & $\square$ & $\square$ & $\square$ & $\square$ \\
\hline $\begin{array}{l}43-\ldots \text { realizar tarefas que exigem o uso das } \\
\text { suas mãos e dedos, como pegar objetos } \\
\text { pequenos ou abrir embalagens? }\end{array}$ & $\square$ & $\square$ & $\square$ & $\square$ & $\square$ \\
\hline 44- ... chegar onde desejava ir? & $\square$ & $\square$ & $\square$ & $\square$ & $\square$ \\
\hline 45- ... usar transportes públicos? & $\square$ & $\square$ & $\square$ & $\square$ & $\square$ \\
\hline 46- ... usar transportes privados? & $\square$ & $\square$ & $\square$ & $\square$ & $\square$ \\
\hline $\begin{array}{l}47-\text {... cuidar da sua saúde, comer bem, } \\
\text { fazer exercício físico ou tomar a sua } \\
\text { medicação? }\end{array}$ & $\square$ & $\square$ & $\square$ & $\square$ & $\square$ \\
\hline 48- ... realizar as suas tarefas domésticas? & $\square$ & $\square$ & $\square$ & $\square$ & $\square$ \\
\hline $\begin{array}{l}49-\ldots \text { prestar cuidados ou ajuda a outra } \\
\text { pessoa? }\end{array}$ & $\square$ & $\square$ & $\square$ & $\square$ & $\square$ \\
\hline $50-\ldots$ interagir com outras pessoas? & $\square$ & $\square$ & $\square$ & $\square$ & $\square$ \\
\hline $51-\ldots$ ter relações sexuais? & $\square$ & $\square$ & $\square$ & $\square$ & $\square$ \\
\hline $\begin{array}{l}52-\text {... fazer coisas que o(a) relaxem ou the } \\
\text { dêem prazer? }\end{array}$ & $\square$ & $\square$ & $\square$ & $\square$ & $\square$ \\
\hline $\begin{array}{l}53-\ldots \text { respirar durante atividades físicas } \\
\text { intensas (falta de ar)? }\end{array}$ & $\square$ & $\square$ & $\square$ & $\square$ & $\square$ \\
\hline $\begin{array}{l}\text { 54- É capaz de se manter sentado(a), sem } \\
\text { apoio? } \\
\square \text { Não } \\
\square \text { Sim > Qual o nível de dificuldade para se } \\
\text { manter sentado(a) por longos períodos como } \\
\text { por exemplo } 30 \text { minutos? }\end{array}$ & $\square$ & $\square$ & $\square$ & $\square$ & $\square$ \\
\hline $\begin{array}{l}\text { 55- É capaz de se manter de pé, sem } \\
\text { apoio? } \\
\square \text { Não } \\
\square \text { Sim > Qual o nível de dificuldade para se } \\
\text { manter de pé por longos períodos como por } \\
\text { exemplo } 30 \text { minutos? }\end{array}$ & $\square$ & $\square$ & $\square$ & $\square$ & $\square$ \\
\hline
\end{tabular}

As próximas perguntas são sobre a sua capacidade de realizar atividades que envolvem mobilidade. Selecione a resposta que melhor descreve a sua capacidade de realizar a atividade sem a ajuda de outra pessoa, mas utilizando o equipamento ou os dispositivos que normalmente usa (por exemplo, tábua de transferências, elevador de transferências, cama elétrica).

Você é capaz de.

\begin{tabular}{|l|c|c|c|c|c|}
\hline & $\begin{array}{c}\text { Sem } \\
\text { qualquer } \\
\text { dificuldade }\end{array}$ & $\begin{array}{c}\text { Com } \\
\text { pouca } \\
\text { dificuldade }\end{array}$ & $\begin{array}{c}\text { Com } \\
\text { alguma } \\
\text { dificuldade }\end{array}$ & $\begin{array}{c}\text { Com muita } \\
\text { dificuldade }\end{array}$ & $\begin{array}{c}\text { Incapaz } \\
\text { de } \\
\text { realizar }\end{array}$ \\
\hline $\begin{array}{l}\text { 56- Levantar-se do } \\
\text { chão se estiver } \\
\text { deitado(a) de costas? }\end{array}$ & $\square$ & $\square$ & $\square$ & $\square$ & $\square$ \\
\hline $\begin{array}{l}\text { 57- Empurrar e abrir } \\
\text { uma porta pesada? }\end{array}$ & $\square$ & $\square$ & $\square$ & $\square$ & $\square$ \\
\hline $\begin{array}{l}\text { 58- Passar da posição } \\
\text { de sentado(a) ao lado } \\
\text { da cama até à posição } \\
\text { de deitado de costas? }\end{array}$ & $\square$ & $\square$ & $\square$ & $\square$ & $\square$ \\
\hline
\end{tabular}

\section{INDEPENDÊNCIA NAS ATIVIDADES DE VIDA DIÁRIA}

Para cada item, por favor marque a resposta que melhor traduza a sua situação atual com um "X". Por favor, leia atentamente o texto e assinale apenas uma resposta em cada seç̧ão.

59- Comer e beber

$\square$ Eu preciso de alimentação artificial ou de um tubo no estômago 
$\square$ Eu preciso de ajuda total a comer/beber (Sou completamente dependente para comer/beber ou Eu preciso de muita ajuda para comer/beber)

$\square$ Eu preciso de ajuda parcial a comer/beber ou para colocar/retirar ajudas técnicas/produtos de apoio (Sou parcialmente dependente para comer/beber ou Eu preciso de um pouco de ajuda para comer/beber)

$\square$ Eu como/bebo de forma independente, mas preciso de ajuda técnicas/produtos de apoio (adaptações) ou ajuda para cortar os alimentos, (servir líquidos ou encher meu copo) ou abrir recipientes/embalagens

$\square$ Eu como/bebo de forma independente, sem ajuda de outra pessoa e sem necessidade de ajuda técnicas/ produtos de apoio (adaptações)

60- Lavar a cabeça e a metade superior do corpo (incluindo se ensaboar, enxaguar, secar e abrir/fechar a torneira)

$\square$ Eu preciso de ajuda total (Sou completamente dependente de ajuda ou Eu preciso de muita ajuda)

$\square$ Eu preciso de ajuda parcial (Sou parcialmente dependente de ajuda ou Eu preciso de um pouco de ajuda)

$\square$ Sou independente, mas preciso de ajudas técnicas/produtos de apoio (adaptações) ou de equipamento específico (cadeira de banho, barras, etc.)

$\square$ Sou independente e não necessito de ajudas técnicas/produtos de apoio (adaptações) ou de equipamento específico

61- Lavar a metade inferior do corpo (incluindo se ensaboar, enxaguar, secar e abrir/fechar a torneira)

$\square$ Eu preciso de ajuda total (Sou completamente dependente de ajuda ou Eu preciso de muita ajuda)

$\square$ Eu preciso de ajuda parcial (Sou parcialmente dependente de ajuda ou Eu preciso de um pouco de ajuda)

$\square$ Sou independente, mas preciso de ajudas técnicas/produtos de apoio (adaptações) ou de equipamento específico (cadeira de banho, barras, etc.)

Sou independente e não necessito de ajudas técnicas/produtos de apoio (adaptações) ou de equipamento específico

62- Vestir a metade superior do corpo - incluindo vestir e despir a roupa, como por exemplo camisetas, blusas, camisas, soutien ou órteses ( $p$. ex. colar cervical, talas para o membro superior ou coletes)

- Roupas fáceis de vestir são aquelas SEM botões, zippers ou cordões

- Roupas difíceis de vestir são aquelas COM botões, zippers ou cordões

$\square$ Eu necessito de ajuda total (Sou completamente dependente de ajuda ou Eu preciso de muita ajuda)

$\square$ Eu necessito de ajuda parcial (Sou parcialmente dependente de ajuda ou Eu preciso de um pouco de ajuda), mesmo com roupas fáceis de vestir

$\square$ Não necessito de ajuda dos outros com roupas fáceis de vestir, mas preciso de ajuda técnicas/produtos de apoio (adaptações) ou de equipamento específico

$\square$ Não necessito de ajuda dos outros com roupas fáceis de vestir, só preciso de ajuda técnicas/produtos de apoio (adaptações) ou de equipamento específico para roupas difíceis de vestir

$\square$ Sou completamente independente

63- Vestir a metade inferior do corpo (incluindo vestir e despir a roupa como por exemplo cuecas, calças, sapatos, meias, cinto ou órteses ( $p$. ex., talas para o membro inferior)

- Roupas fáceis de vestir são aquelas SEM botões, zippers ou cordões

- Roupas difíceis de vestir são aquelas COM botões, zippers ou cordões

$\square$ Eu necessito de ajuda total (Sou completamente dependente de ajuda ou Eu preciso de muita ajuda)

$\square$ Eu necessito de ajuda parcial (Sou parcialmente dependente de ajuda ou Eu preciso de um pouco de ajuda), mesmo com roupas fáceis de vestir

$\square$ Não necessito de ajuda dos outros com roupas fáceis de vestir, mas preciso de ajuda técnicas/produtos de apoio (adaptações) ou de equipamento específico

$\square$ Não necessito de ajuda dos outros com roupas fáceis de vestir, só preciso de ajuda técnicas/produtos de apoio (adaptações) ou de equipamento específico para roupas difíceis de vestir

$\square$ Sou completamente independente

64- Higiene pessoal (por favor pense em atividades tais como lavar as mãos e o rosto, escovar os dentes, pentear o cabelo, barbear-se ou maquiar-se)

$\square$ Eu necessito de ajuda total (Sou completamente dependente de ajuda ou Eu preciso de muita ajuda)

$\square$ Eu necessito de ajuda parcial (Sou parcialmente dependente de ajuda ou Eu preciso de um pouco de ajuda)

$\square$ Sou independente com ajuda técnicas/produtos de apoio (adaptações)

$\square$ Sou independente mesmo sem ajudas técnicas/produtos de apoio (adaptações)

65- Controle da bexiga (por favor, pense na forma como esvazia a sua bexiga)

A) Usa uma sonda de alívio contínuo?

$\square$ Sim. Por favor, passe direto para a questão $n^{\circ} 66$

$\square$ Não. Por favor, responda às questões $B$ e $C$

B) Sonda intermitente

$\square$ Preciso de ajuda total (Sou completamente dependente de ajuda ou Eu preciso de muita ajuda) (a passagem da sonda é realizada por outra pessoa)

$\square$ Faço eu próprio, mas com ajuda (auto-sondagem)

$\square$ Faço eu próprio, sem precisar de ajuda (auto-sondagem)

\section{$\square$ Não utilizo sondagem intermitente}

C) Uso de dispositivos externos para drenagem da urina ou materiais protetores (por exemplo: fraldas, coletores, dispositivos do tipo preservativo e protetores (por
absorventes)

$\square$ Preciso de ajuda total para a sua utilização (Sou completamente dependente de ajuda ou Eu preciso de muita ajuda)

$\square$ Preciso de ajuda parcial para a sua utilização (Sou parcialmente dependente de ajuda ou Eu preciso de um pouco de ajuda)

$\square$ Uso, sem necessitar de ajuda

$\square$ Sou continente (não tenho perdas urinárias) e não uso dispositivos externos para drenagem

66- Controle do intestino

A) Necessita de ajuda com o esvaziamento intestinal (por exemplo, para aplicar supositórios)?

$\square \operatorname{Sim}$

$\square$ Não

B) O meu trânsito intestinal é...

$\square$ Irregular e lento (menos de 1 vez a cada 3 dias)

$\square$ Regular (pelo menos 1 vez a cada 3 dias)

C) Episódios de incontinência fecal (“acidentes”, “perdas”) acontecem...

$\square$ Diariamente

$\square$ 1-6 vezes por semana

$\square$ 1-4 vezes por mês

$\square$ Menos de 1 vez por mês

$\square$ Nunca acontecem

67- Uso de vaso sanitário (Higiene íntima) (por favor, pense no uso do vaso sanitário, na limpeza dos genitais e das mãos, em se despir e se vestir, e no uso de fraldas e absorventes)

$\square$ Preciso de ajuda total (Sou completamente dependente de ajuda ou Eu preciso de muita ajuda)

$\square$ Preciso de ajuda parcial (Sou parcialmente dependente de ajuda ou Eu preciso de um pouco de ajuda) e não consigo me limpar

$\square$ Preciso de ajuda parcial (Sou parcialmente dependente de ajuda ou Eu preciso de um pouco de ajuda), mas consigo me limpar

$\square$ Não necessito de ajuda de outra pessoa, mas necessito de ajudas técnicas/produtos de apoio (adaptações como, por exemplo, barras de apoio) ou um local adaptado (por exemplo, banheiro acessível a cadeira de rodas)

$\square$ Não necessito de qualquer ajuda, ajudas técnicas/produtos de apoio ou local adaptado

68- Qual ou quais das seguintes atividades consegue desempenhar sem ajuda de outra pessoa ou ajudas técnicas/dispositivos de apoio elétricos? Assinale todas as opções que se apliquem

$\square$ Virar a parte superior do corpo na cama

$\square$ Virar a parte inferior do corpo na cama

$\square$ Sentar-se na cama

$\square$ Fazer push-ups (elevações) numa cadeira ou na cadeira de rodas

$\square$ Nenhum. Necessito de ajuda em todas as atividades descritas acima.

\section{9- Transferências da cama para a cadeira de rodas}

$\square$ Necessito de ajuda total (Sou completamente dependente de ajuda ou Eu preciso de muita ajuda)

$\square$ Necessito de ajuda parcial (Sou parcialmente dependente de ajuda ou Eu preciso de um pouco de ajuda), supervisão ou ajudas técnicas/produtos de apoio (por exemplo, tábua de transferência)

$\square$ Não necessito de ajuda de outra pessoa ou de ajudas técnicas/produtos de apoio

Não uso cadeira de rodas

70- Mobilidade para distâncias moderadas (10 a 100 metros)

Eu uso uma cadeira de rodas. Para me deslocar..

$\square$ Necessito de ajuda total (Sou completamente dependente de ajuda ou Eu preciso de muita ajuda)

$\square$ Necessito de uma cadeira de rodas motorizada ou de um pouco de ajuda para usar uma cadeira de rodas manual

$\square$ Sou independente em uma cadeira de rodas manual

Eu caminho distâncias moderadas e..

$\square$ Necessito de supervisão (presença de outra pessoa) enquanto caminho (quer seja com ou sem meios auxiliares para a marcha/produtos de apoio)

$\square$ Caminho com andador ou muletas (lançando as pernas para a frente, ao mesmo tempo)

$\square$ Caminho com muletas ou duas bengalas (avançando uma perna de cada vez)

$\square$ Caminho com uma bengala

$\square$ Caminho usando apenas órtese(s) (talas) nos membros inferiores

$\square$ Caminho sem meios auxiliares para a marcha/produtos de apoio

\section{TRABALHO}

71- Qual era a sua profissão/emprego antes da lesão medular?

$\square$ Não tinha um emprego antes da lesão medular 
72- Você recebeu reabilitação profissional após a sua lesão medular? (por exemplo: aconselhamento ou treinamento profissional, treinamento em uma nova profissão)

$\square \operatorname{Sim}$

$\square$ Não

73- Após a sua alta do processo inicial de reabilitação (em regime de internação), quanto tempo demorou até começar ou retomar um trabalho internação), qu

$\square$ Nunca trabalhei desde a alta do tratamento inicial de reabilitação (em regime de internação)

$\square$ Comecei a trabalhar logo após a alta do tratamento inicial de reabilitação (em regime de internação)

$\square$ Retomei o trabalho depois de anos e meses

74- Você recebe atualmente algum benefício previdenciário relacionado à sua deficiência?

$\square \mathrm{Sim}$

$\square$ Não

75- Qual é a sua situação laboral atual?

Assinale todas as opções que se aplicam

$\square$ Empregado por outras pessoas em troca de um salário ou remuneração, trabalhando horas por semana

$\square$ Empregado por outras pessoas em troca de um salário ou remuneração, trabalhando ___ horas por semana, mas atualmente afastado do trabalho

$\square$ Trabalhando por conta própria, durante_horas por semana

$\square$ Empregado em um negócio de família (sem salário ou remuneração)

$\square$ Doméstico/doméstica (dono(a) de casa)

$\square$ Estudante

$\square$ Desempregado

$\square$ Aposentado por invalidez

$\square$ Aposentado por idade

$\square$ Outro, por favor especifique

76- Atualmente, você exerce um trabalho remunerado (com pagamentos)? $\square$ Sim

$\square$ Não. Por favor, passe direto à pergunta $n^{\circ} 84$

77- Qual é a sua profissão/emprego atual (por favor, seja específico):

78- Desejaria trabalhar mais horas, menos horas ou o mesmo número de horas que trabalha atualmente?

$\square$ Mais horas

$\square$ Menos horas

$\square$ O mesmo número de horas

79- Quão problemático é para você fazer as coisas que lhe são exigidas no trabalho?

1- Sem Problema e 5 - Muito problemático

$\begin{array}{llll}2 & 3 & 4 & 5\end{array}$

80- Quão problemático é para você ter acesso ao local de trabalho? (por exemplo, acesso ao edifício, ao seu escritório ou ao banheiro)

1- Sem Problema e 5 - Muito problemático

$1+2 \quad 3 \quad 4 \quad 5$

81- Tem os produtos de apoio/ajudas técnicas de que necessita para trabalhar? (por exemplo, computadores adaptados, mesas ajustáveis, talas ou próteses para antebraço e mão)

$\square$ Completamente

$\square$ Em grande medida

$\square$ Até certo ponto

$\square$ Em pequena medida

$\square$ Não

$\square$ Não necessito de produtos de apoio/ajuda técnicas para o trabalho

As 2 questões seguintes referem-se ao seu emprego atual. Para cada uma das frases indique se concorda totalmente, concorda, discorda ou discorda totalmente.

82- Recebo o reconhecimento que mereço pelo meu trabalho.

$\square$ Concordo totalmente

$\square$ Concordo

$\square$ Discordo

$\square$ Discordo totalmente

83- Considerando todos os meus esforços e conquistas, o meu salário é adequado.

$\square$ Concordo totalmente

$\square$ Concordo

$\square$ Discordo
Por favor, passe diretamente para a pergunta $n^{\circ} 87$

84- Gostaria de ter um trabalho pago?

$\square \operatorname{Sim}$

$\square$ Não

85- Você acha que tem capacidade para realizar um trabalho pago?

$\square$ Sim, durante 1 a 11 horas por semana

$\square$ Sim, durante 12 a 20 horas por semana

$\square$ Sim, durante mais de 20 horas por semana

$\square$ Não, é impossível

86- Quais são os motivos pelos quais não está trabalhando atualmente? (assinale todos os que se aplicarem)

$\square$ Condição de saúde ou deficiência

$\square$ Ainda frequentando formação escolar ou profissiona

$\square$ Responsabilidades familiares pessoais

$\square$ Não consegui encontrar trabalho que seja capaz de desempenhar

$\square$ Não sei como ou onde procurar trabalho

$\square$ Não tenho necessidades econômicas

$\square$ Pais ou cônjuge (esposo/a) não me deixam trabalhar

$\square$ Serviço de transportes insuficiente

$\square$ Falta de acessibilidade nos locais de trabalho (por exemplo, ao edifício, ao escritório ou aos banheiros)

$\square$ Falta de produtos de apoio/ajuda técnicas

$\square$ Medo de perder benefícios previdenciários (por exemplo, subsídios, pensões, indenização de seguradoras)

$\square$ Não quero trabalhar

$\square$ Outro, por favor especifique:

\section{FATORES AMBIENTAIS}

$\mathrm{Na}$ vida diária estamos expostos a diversas influências externas ou fatores ambientais. Estes podem tornar a vida diária mais fácil ou mais difícil. Pense nas últimas 4 semanas e classifique o quanto estes fatores ambientais influenciaram a sua participação na sociedade.

\begin{tabular}{|c|c|c|c|c|}
\hline & $\begin{array}{c}\text { Não } \\
\text { aplicável }\end{array}$ & $\begin{array}{c}\text { Sem } \\
\text { influência }\end{array}$ & $\begin{array}{c}\text { Tornou a } \\
\text { minha } \\
\text { vida um } \\
\text { pouco } \\
\text { mais } \\
\text { dificil } \\
\end{array}$ & $\begin{array}{l}\text { Tornou a } \\
\text { minha } \\
\text { vida } \\
\text { muito } \\
\text { mais } \\
\text { difícil }\end{array}$ \\
\hline $\begin{array}{l}\text { 87- Sem acessibilidade ou } \\
\text { acessibilidade insuficiente } \\
\text { em locais públicos (por } \\
\text { exemplo, } \\
\text { edifícios públicos ou parques } \\
\text { inacessiveis) }\end{array}$ & $\square$ & $\square$ & $\square$ & $\square$ \\
\hline $\begin{array}{l}\text { 88- Sem acessibilidade ou } \\
\text { acessibilidade insuficiente } \\
\text { na casa de amigos e } \\
\text { familiares }\end{array}$ & $\square$ & $\square$ & $\square$ & $\square$ \\
\hline $\begin{array}{l}89 \text { - Condições climáticas } \\
\text { desfavoráveis (por exemplo, } \\
\text { condições meteorológicas, } \\
\text { estação do ano, temperatura, } \\
\text { humidade) }\end{array}$ & $\square$ & $\square$ & $\square$ & $\square$ \\
\hline $\begin{array}{l}\text { 90- Atitude negativa da } \\
\text { sociedade para com as } \\
\text { pessoas com deficiência } \\
\text { (por exemplo, preconceito, } \\
\text { estigma, ignorância) }\end{array}$ & $\square$ & $\square$ & $\square$ & $\square$ \\
\hline $\begin{array}{l}\text { 91- Atitude negativa da sua } \\
\text { familia e parentes para com } \\
\text { a sua deficiência (por } \\
\text { exemplo, preconceito, falta de } \\
\text { apoio, comportamentos super } \\
\text { protetores) }\end{array}$ & $\square$ & $\square$ & $\square$ & $\square$ \\
\hline $\begin{array}{l}\text { 92- Atitude negativa dos } \\
\text { seus amigos para com a sua } \\
\text { deficiência (por exemplo, } \\
\text { preconceito, falta de } \\
\text { apoio, comportamentos super } \\
\text { protetores) }\end{array}$ & $\square$ & $\square$ & $\square$ & $\square$ \\
\hline $\begin{array}{l}\text { 93- Atitude negativa de } \\
\text { vizinhos, conhecidos e } \\
\text { colegas de trabalho para } \\
\text { com a sua deficiência } \\
\text { (por exemplo, preconceito, } \\
\text { falta de apoio, } \\
\text { comportamentos super } \\
\text { protetores) }\end{array}$ & $\square$ & $\square$ & $\square$ & $\square$ \\
\hline
\end{tabular}




\begin{tabular}{|c|c|c|c|c|}
\hline \begin{tabular}{|l|} 
94- Ausência ou \\
insuficiência de adaptações \\
tecnológicas que permitam \\
deslocar-se por curtas \\
distâncias (por exemplo, falta \\
ou insuficiência de cadeira de \\
rodas, meios auxiliares para a \\
marcha ou elevador para \\
escadas)
\end{tabular} & $\square$ & $\square$ & $\square$ & $\square$ \\
\hline \begin{tabular}{|l|} 
95- Ausência ou adaptação \\
inadequada dos meios de \\
transporte para longas \\
distâncias (por exemplo, falta \\
de carro adaptado ou \\
transportes públicos difíceis \\
de usar) \\
\end{tabular} & $\square$ & $\square$ & $\square$ & $\square$ \\
\hline $\begin{array}{l}\text { 96- Ausência ou } \\
\text { insuficiência de serviços de } \\
\text { enfermagem ou cuidados } \\
\text { diários (por exemplo, } \\
\text { cuidados domiciliares ou } \\
\text { assistência pessoal) }\end{array}$ & $\square$ & $\square$ & $\square$ & $\square$ \\
\hline $\begin{array}{l}\text { 97- Ausência ou } \\
\text { insuficiência de medicação } \\
\text { ou equipamentos (por } \\
\text { exemplo, falta de sondas, } \\
\text { desinfetantes, talas, } \\
\text { almofadas, etc.) }\end{array}$ & $\square$ & $\square$ & $\square$ & $\square$ \\
\hline $\begin{array}{l}\text { 98- Situação financeira } \\
\text { problemática (falta de } \\
\text { dinheiro) }\end{array}$ & $\square$ & $\square$ & $\square$ & $\square$ \\
\hline \begin{tabular}{|l|} 
99- Ausência ou \\
insuficiência de dispositivos \\
de comunicação (por \\
exemplo, dispositivos para a \\
escrita, computador, telefone)
\end{tabular} & $\square$ & $\square$ & $\square$ & $\square$ \\
\hline \begin{tabular}{|l|}
$100-$ Ausência ou \\
insuficiência de serviços \\
públicos (por exemplo, \\
pensão por invalidez ou \\
benefícios previdenciários)
\end{tabular} & $\square$ & $\square$ & $\square$ & $\square$ \\
\hline
\end{tabular}

\section{SERVIÇOS DE SAÚDE}

101- Quem foram os prestadores de cuidados de saúde que você visitou, ou que o(a) visitaram na sua casa, nos últimos 12 meses? (assinale todos os que se apliquem)

$\square$ Médico(a) de família/Clínico geral

$\square$ Fisiatra/médico(a) especialista em reabilitação do lesionado medular

$\square$ Outro(a) médico(a) especialista (por exemplo: cirurgião, ginecologista, psiquiatra, oftalmologista, etc.)

$\square$ Enfermeiro(a) ou parteira/obstetriz

$\square$ Dentista

$\square$ Fisioterapeut

$\square$ Quiroprata

$\square$ Terapeuta ocupacional

$\square$ Psicólogo(a)

$\square$ Técnico de terapias alternativas (como por ex. Acupunturista ou Naturopata)

$\square$ Farmacêutico ou técnico de farmácia

$\square$ Serviços/cuidados domiciliares

$\square$ Outro, por favor especifique:

$\square$ Não visitei nenhum prestador de cuidados/serviços de saúde nos últimos 12 meses

102- Nos últimos 12 meses, quantas vezes esteve internado(a) pelo menos uma noite num hospital, centro de reabilitação ou outro serviço de saúde? vezes

Analisando a sua última visita a um prestador de cuidados/serviços de saúde, como você pontuaria as seguintes experiências:

103- Foi tratado(a) respeitosamente?

$\square$ Muito bem

$\square$ Bem

$\square$ Nem bem nem mal

$\square$ Mal

$\square$ Muito mal

104- Quão claramente os prestadores de cuidados/serviços de saúde the explicaram as coisas?

$\square$ Muito bem

$\square$ Bem

$\square$ Nem bem nem mal

$\square$ Mal

$\square$ Muito mal

105- Foi envolvido(a) nas decisões do seu próprio tratamento? $\square$ Muito bem

$\square$ Bem $\square$ Nem bem nem mal

$\square$ Mal

$\square$ Muito mal

106- Nos últimos 12 meses, alguma vez necessitou de cuidados/serviços de saúde, mas não os conseguiu?

$\square$ Não

$\square$ Sim. Quais os motivos que melhor explicam o fato de não ter conseguido os cuidados de saúde de que necessitava?

Assinale todas as opções que se aplicam.

$\square$ Não consegui pagar o preço dos cuidados (consulta, tratamentos)

$\square$ Não existia um serviço capaz de prestar esses cuidados

$\square$ Não havia transporte disponível

$\square$ Não consegui pagar os custos do transporte

$\square$ Fui mal tratado anteriormente

$\square$ Não consegui arranjar tempo (por motivos de trabalho ou outros compromissos)

$\square$ Os equipamentos do prestador de cuidados de saúde ou os medicamentos eram inadequados

$\square$ Os conhecimentos e capacidades do prestador de cuidados de saúde eram inadequados

$\square$ Não sabia para onde ir

$\square$ Tentei, mas foram-me negados os cuidados de saúde

$\square$ Achei que não estava suficientemente doente

$\square$ Outro, por favor especifique:

107- Em geral, quão satisfeito(a) está com a forma como os serviços e cuidados de saúde funcionam na sua área?

$\square$ Muito satisfeito

$\square$ Satisfeito

$\square$ Nem satisfeito nem insatisfeito

$\square$ Insatisfeito

$\square$ Muito insatisfeito

\section{FATORES PESSOAIS}

As questões a seguir são sobre como você se vê.

1 - Nem um pouco e 5 - Completamente

\begin{tabular}{|l|l|l|l|l|l|}
\hline & 1 & 2 & 3 & 4 & 5 \\
\hline $\begin{array}{l}\text { 108- Quão confiante você está de que } \\
\text { pode encontrar os meios e as formas de } \\
\text { conseguir o que você quer se alguém se } \\
\text { opuser a isso? }\end{array}$ & $\square$ & $\square$ & $\square$ & $\square$ & $\square$ \\
\hline $\begin{array}{l}\text { 109- Quão confiante você está de que } \\
\text { consegue lidar eficazmente com } \\
\text { acontecimentos inesperados? }\end{array}$ & $\square$ & $\square$ & $\square$ & $\square$ & $\square$ \\
\hline $\begin{array}{l}\text { 110- Quão confiante você está de que } \\
\text { consegue manter contato com pessoas } \\
\text { que são importantes para você? }\end{array}$ & $\square$ & $\square$ & $\square$ & $\square$ & $\square$ \\
\hline $\begin{array}{l}\text { 111- Quão confiante você está de que } \\
\text { consegue se manter saudável? }\end{array}$ & $\square$ & $\square$ & $\square$ & $\square$ & $\square$ \\
\hline $\begin{array}{l}\text { 112- Você acha que viver com a sua } \\
\text { lesão medular o(a) tornou numa pessoa } \\
\text { mais forte? }\end{array}$ & $\square$ & $\square$ & $\square$ & $\square$ & $\square$ \\
\hline $\begin{array}{l}\text { 113- Você se preocupa com o que Ihe } \\
\text { possa vir a acontecer no futuro? (como } \\
\text { por exemplo, ter receio de não ser capaz de } \\
\text { cuidar de si mesmo ou de se tornar um peso } \\
\text { para os outros) }\end{array}$ & $\square$ & $\square$ & $\square$ & $\square$ & $\square$ \\
\hline $\begin{array}{l}\text { 114- Você acha que será capaz de } \\
\text { alcançar os seus sonhos, esperanças e } \\
\text { desejos? }\end{array}$ & $\square$ & $\square$ & $\square$ & $\square$ & $\square$ \\
\hline $\begin{array}{l}\text { 115- Você consegue tomar as grandes } \\
\text { decisões da sua vida? (por exemplo, } \\
\text { decidir onde vive, com quem vive, como } \\
\text { gasta o seu dinheiro) }\end{array}$ & $\square$ & $\square$ & $\square$ & $\square$ & $\square$ \\
\hline $\begin{array}{l}\text { 116- Sente-se incluído(a) quando está } \\
\text { com outras pessoas? }\end{array}$ & $\square$ & $\square$ & $\square$ & $\square$ & $\square$ \\
\hline
\end{tabular}

117- Nos últimos 12 meses, passou por algum importante acontecimento desagradável na sua vida? 
Por exemplo: uma doença grave, um acidente, divórcio, morte de um ente querido ou conflitos graves com outra pessoa.

$\square$ Não

Sim. Por favor, especifique:

\section{QUALIDADE DE VIDA E SAÚDE EM GERAL}

As questões a seguir são sobre como você pontua a sua qualidade de vida de uma forma geral e em algumas áreas da sua vida em particular. Por favor pense na sua vida nos últimos 14 dias. Pense nos seus padrões, esperanças, prazeres e preocupações.

Nos últimos 14 dias...

118- Como classifica a sua qualidade de vida?

$\square$ Muito má

$\square$ Má

$\square$ Nem boa nem má

$\square$ Boa

$\square$ Muito boa

119- Está satisfeito(a) com a sua saúde?

$\square$ Muito insatisfeito

$\square$ Insatisfeito

$\square$ Nem satisfeito nem insatisfeito

$\square$ Satisfeito

$\square$ Muito satisfeito

120- Está satisfeito(a) com a sua capacidade para desempenhar as atividades do seu dia-a-dia?

$\square$ Muito insatisfeito

$\square$ Insatisfeito

$\square$ Nem satisfeito nem insatisfeito

$\square$ Satisfeito

$\square$ Muito satisfeito
121- Está satisfeito(a) consigo mesmo(a)?

$\square$ Muito insatisfeito

$\square$ Insatisfeito

$\square$ Nem satisfeito nem insatisfeito

$\square$ Satisfeito

$\square$ Muito satisfeito

122- Está satisfeito(a) com os seus relacionamentos pessoais?

$\square$ Muito insatisfeito

$\square$ Insatisfeito

$\square$ Nem satisfeito nem insatisfeito

$\square$ Satisfeito

$\square$ Muito satisfeito

123- Está satisfeito(a) com as suas condições de vida?

$\square$ Muito insatisfeito

$\square$ Insatisfeito

$\square$ Nem satisfeito nem insatisfeito

$\square$ Satisfeito

$\square$ Muito satisfeito

124- Em geral, diria que a sua saúde é:

$\square$ Excelente

$\square$ Muito boa

$\square$ Boa

$\square$ Razoáve

$\square$ Ruim

125- Em comparação a 1 ano atrás, como diria que está a sua saúde em geral atualmente?

$\square$ Muito melhor

$\square$ Um pouco melhor

$\square$ Na mesma

$\square$ Um pouco pior

$\square$ Muito pior 